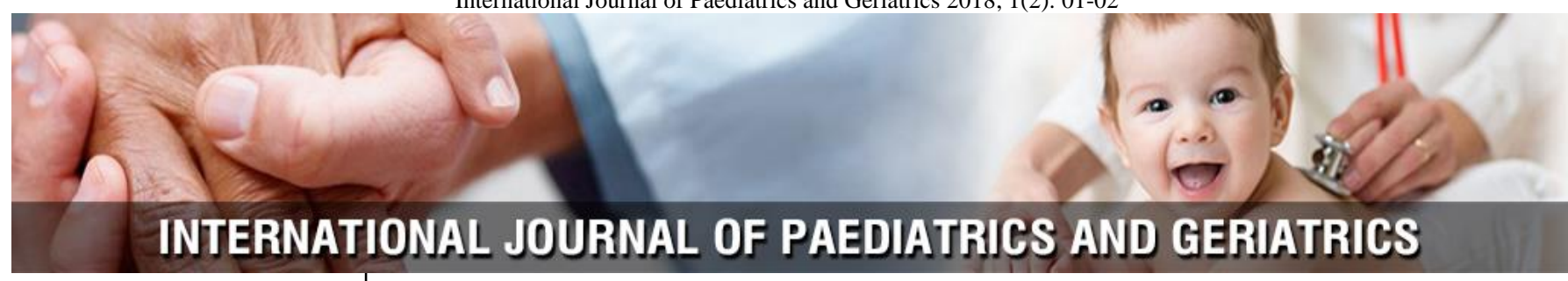

P-ISSN: 2664-3685

E-ISSN: $2664-3693$

www.paediatricjournal.com

IJPG 2018; 1(2): 01-02

Accepted: 07-06-2018

Dr. Jagdish Aggarwal

Department of Paediatrics, Sri

Balaji Action Medical

Institute, Delhi, India
Received: 05-05-2018

\section{Evaluation of 26 cases of dengue fever in children}

\section{Dr. Jagdish Aggarwal}

DOI: https://doi.org/10.33545/26643685.2018.v1.i2a.9

\begin{abstract}
Background: Dengue virus infection presents with a diverse clinical picture. The present study was conducted to evaluate the cases of dengue in children.

Materials \& Methods: The present study was conducted on 26 cases of dengue fever of both genders. Based on history of illness, patients were tested for NS1 Ag - illness less than 5 days, NS1 Ag \& IgM $\mathrm{Ab}$ - illness between 5-7 days, and IgM Ab - illness more than 7 days.

Results: Out of 26 cases, males were 16 and female were 10. Common clinical features in patients were fever seen in all 26, skin rashes in 22, myalgia in 17 and headache in 16 . The difference was nonsignificant $(\mathrm{P}>0.05)$.

Conclusion: Authors found 26 cases of dengue fever. Common clinical features were fever, skin rashes, myalgia and headache.
\end{abstract}

Keywords: Dengue fever, Myalgia, Rashes.

\section{Introduction}

The dengue virus, a member of the genus Flavivirus of the family Flaviviridae, is an arthropode-borne virus that includes four different serotypes (DEN-1, DEN-2, DEN-3, and DEN-4). The first reported case of dengue like illness in India was in Madras in 1780, the first virologically proved epidemic of DF in India occurred in Calcutta and Eastern Coast of India in 1963-1964. Dengue virus infection presents with a diverse clinical picture that ranges from asymptomatic illness to DF to the severe illness of dengue hemorrhagic fever/dengue shock syndrome (DHF/DSS) ${ }^{[1]}$.

Dengue fever, also known as breakbone fever, is a mosquito-borne infectious tropical disease caused by the dengue virus. This disease occurs primarily in the equatorial regions of Africa, the Americas, South-East Asia, and the Western Pacific ${ }^{[2]}$. The incidence of dengue fever has increased dramatically since the 1960 s, with current estimates of incidence ranging from 50 million2 to 528 million3 people infected yearly. This increase is believed to be due to several factors, including global warming and urbanization. Early descriptions of the condition date from 1779, and its viral cause and mechanism of transmission were elucidated in the early 20th century. Dengue has become a global problem since the Second World War and is endemic in more than 110 countries. Symptoms include fever, headache, muscle and joint pains, and a characteristic skin rash that is similar to measles ${ }^{[3]}$. The present study was conducted to evaluate the cases of dengue in children.

\section{Materials \& Methods}

The present study was conducted in the department of Pediatrics. It comprised of 26 cases of dengue fever of both genders. Patients were informed regarding the study and written consent was obtained. Ethical approval was obtained prior to the study.

Data related to patients such as name, age, gender etc. was recorded. Based on history of illness, patients were tested for NS1 Ag-illness less than 5 days, NS1 Ag \& IgM Ab-illness between 5-7 days, and IgM Ab-illness more than 7 days. The IgM dengue ELISA capture test kits were used for the study. Dengue NS1 antigen capture ELISA assay was performed by Platelia Dengue NS1 Ag. Data was tabulated and subjected to statistical analysis. P value less than 0.05 was considered significant.

\section{Results}

Table 1: Distribution of patients

\begin{tabular}{|c|c|c|}
\hline \multicolumn{3}{|c|}{ Total- 26 } \\
\hline Gender & Males & Females \\
\hline Number & 16 & 10 \\
\hline
\end{tabular}


Table I shows that out of 26 cases, males were 16 and female were 10 .

Table 2: Clinical features of patients

\begin{tabular}{|c|c|c|}
\hline Clinical features & Number & \multirow{2}{*}{ P value } \\
\hline Skin rashes & 22 & \multirow{2}{*}{0.51} \\
\hline Fever & 26 & \\
\hline Myalgia & 17 & \\
\hline Headache & 16 & \\
\hline
\end{tabular}

Table II shows that common clinical features in patients were fever seen in all 26, skin rashes in 22, myalgia in 17 and headache in 16. The difference was non- significant $(P>0.05)$.

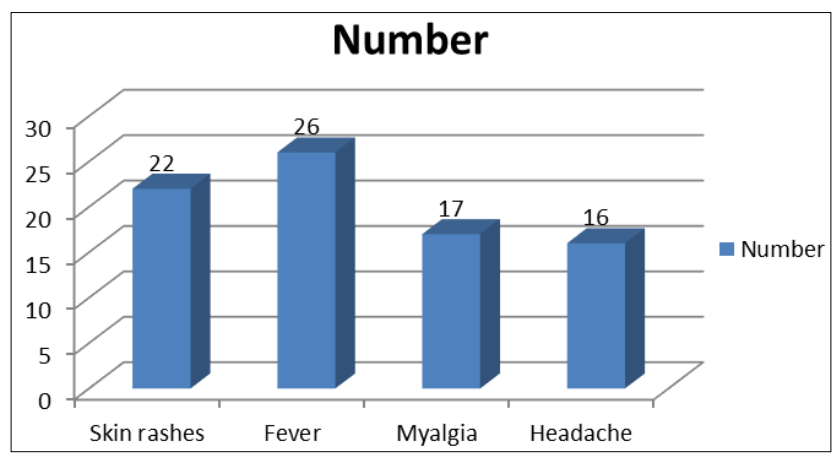

Graph 1: Clinical features of patients

\section{Discussion}

Dengue virus gains entry into the host organism through the skin following an infected mosquito bite. Humoral, cellular, and innate host immune responses are implicated in the progression of the illness and the more severe clinical signs occur following the rapid clearance of the virus from the host organism. Hence, the most severe clinical presentation during the infection course does not correlate with a high viral load ${ }^{[4]}$.

Alterations in endothelial microvascular permeability and thromboregulatory mechanisms lead to an increased loss of protein and plasma. Proposed theories suggest that endothelial cell activation caused by monocytes, T- cells, the complement system, and various inflammatory molecules mediate plasma leakage. Thrombocytopenia may be related to alterations in megakaryocytopoiesis, manifested by infection of human hematopoietic cells and compromised progenitor cell growth. This may cause platelet dysfunction, damage, or depletion, leading to significant hemorrhages ${ }^{[5]}$.

Dengue is transmitted by several species of mosquito within the genus Aedes, principally Aedes aegypti. The virus has 5 different types; infection with a given type usually confers lifelong immunity to that type, but only short-term immunity to the others. Subsequent infection with a different type increases the risk of severe complications. As there is no commercially available vaccine, prevention is sought by reducing the habitat and the number of mosquitoes and limiting exposure to bites ${ }^{[6]}$.

In present study, out of 26 cases, males were 16 and female were 10 . The common clinical features in patients were fever seen in all 26, skin rashes in 22, myalgia in 17 and headache in 16 . The difference was non- significant $(P>0.05)$.

Wu et $a l^{[7]}$. Conducted a study in which patients were tested for NS1 Ag, IgM Ab or both. Out of 4216 samples, 1072 (25.4\%) were positive for dengue. Positivity ranged from
$44.1 \%$ in year $2013,25.8 \%$ in 2015 to $16.1 \%$ in year 2017 . Most cases reported were among male $(57.9 \%)$, from urban areas $(77.9 \%)$ and Rajkot district $(75.7 \%)$. Reporting of dengue cases increased from July to November with peak during October every year. Serum samples for dengue serology were more commonly positive in July-September Months during the study period, and in male children, and those from urban areas.

DF follows both primary and secondary infections, and is most frequently encountered in adults and older children ${ }^{[8]}$. Onset of symptoms is characterized by a biphasic, high-grade fever lasting for 3 days to 1 week. Severe headache (mainly retrobulbar), lassitude, myalgia and painful joint, metallic taste, apetite loss, diarrhea, vomiting, and stomachache are the other reported manifestations. Dengue is also known as breakbone fever because of the associated myalgia and pain in joints. Of patients with DF, $50-82 \%$ report with a peculiar cutaneous rash ${ }^{[9]}$.

\section{Conclusion}

Authors found 26 cases of dengue fever. Common clinical features were fever, skin rashes, myalgia and headache.

\section{References}

1. Guzman MG, Halstead SB, Artsob H, Buchy P, Farrar J, Gubler DJ, et al. Dengue: A continuing global threat. Nat Rev Microbiol. 2010; 8:7-16.

2. Linares EM, Pannuti CS, Kubota LT, Thalhammer S. Immunospot assay based on fluorescent nanoparticles for dengue fever detection. Biosens Bioelectron.2013; 41:180-5.

3. San Martin JL, Brathwaite O, Zanbrano B, Solorzano JO, Bouckenooghe A, Dayan GH, et al. The epidemiology of dengue in the Americas over the last three decades: A worrisome reality.

4. Am J Tropical Med Hyg. 2010; 82:128-35.

5. Gupta N, Srivastava S, Jain A, Chaturvedi UC. Dengue in India. Indian J Med Res. 2012; 136:373-90.

6. Thomas EA, John M, Bhatia A. Muco-Cutaneous manifstations of dengue viral infection in Punjab. Int $\mathbf{J}$ Dermatol. 2007; 46:715-19.

7. Arshad I, Malik FA, Hussain A, Shah SA. Dengue fever: Clinico- pathologic correlations and their association with poor outcome. Professional Med J. 2011; 18:57-63.

8. Wu SJ, Grouard- Vigel G, Sun W, Mascola JR, Brachel E, Putvatana R, et al. Human skin langerhans cells are targets of dengue virus infection. Nat Med. 2000; 6:816-20.

9. Bhamarapravati N. Pathology and Pathogenesis of DHF. New Delhi: WHO Meeting, 1980.

10. Whitehorn J, Simmons CP. The pathogenesis of dengue. Vaccine. 2011; 29:7221-8. 